\title{
Determination of mRNA three Toll-like receptors in human carcinoma cell lines
}

\author{
BARTOSZ BRZEZICHA ${ }^{\prime}$, JOANNA BUDNA ${ }^{\prime}$, MAGDALENA FRYDRYCHOWICZ', \\ AGATA KOLECKA' ${ }^{l}$ IWONA MOZER-LISEWSKA ${ }^{2}$, JAN SIKORA ${ }^{l}$, JAN ŻEROMSKI
}

${ }^{1}$ Chair and Department of Clinical Immunology, Poznan University of Medical Sciences, Poznań, Poland

${ }^{2}$ Department of Infectious Diseases, Poznan University of Medical Sciences, Poznań, Poland

\begin{abstract}
Toll-like receptors (TLRs) are now considered to be active players in tumor-host interactions. Tolllike receptor protein expression on/in cancer cell depends apparently on the level of RNA transcription. Based on previous work showing presence of TLR $m R N A$ in six carcinoma cell lines, it was attempted to determine quantitatively mRNA of TLR-2, TLR-3 and TLR-4 by rt PCR. It has been shown that the expression of mRNA of three TLRs tested was uneven among examined cell lines. These data imply that in any future anti-tumor immunotherapeutic trials involving TLRs it seems mandatory to determine precisely TLR mRNA of cancer cells.
\end{abstract}

Key words: Toll-like receptors, quantitative rt PCR, $m R N A$, human cancer cell lines.

\section{Introduction}

Toll-like receptors (TLRs) are now well established factors of cell contacts with surrounding environment. Cells are able to recognize pathogens possessing pathogen associated molecular patterns (PAMPs) by virtue of TLRs and mount against them suitable protection, often an immune response. Owing to the work of recent Nobel laureates, in particular, dr. Bruce Beutler, and others, we became aware of the significance of pattern recognition receptors (PRRs) and in particular TLRs' close links between generation of infection and TLR reactivity at the level of the genome in the infected cell $[1,2]$.

The knowledge of the role of TLRs on the growth and proliferation of cancer cell is much less known. Nevertheless, the expression of various subtypes of TLRs has been documented in cells of several human cancers, such as those of head and neck, lung, liver and others [3, 4]. Some TLRs, such as TLR-7/8 have been shown to be an advantage for tumor growth [5]. Other authors provided some evidence that tumor bound TLRs treated with their ligands may inhibit spreading of tumor [6, 7]. The expression of TLRs, at least in some cancers may be universal, as it was shown by us in laryngeal cancer. We were able to demonstrate mRNA in head and neck cancer cell lines for all TLRs studied (TLR-1 to
TLR-10) by rt PCR qualitative assay. We noticed, however, differences in the intensity of individual mRNA lines [8]. Such differences may have significant impact on cell-cell interactions in the attempts of immunotherapy involving TLRs. Thus, it was decided to determine quantitatively mRNA content in studied cell lines of three the most frequently studied TLRs i.e. TLR-2, TLR-3 and TLR-4 in order to search their possible potential in therapeutic attempts in the interactions of TLRs - TLR ligands.

\section{Material and methods}

\section{Cell lines culture}

The same head and neck carcinoma cell lines as studied previously [8] have been used. They originated from Pittsburgh Cancer Institute (USA) generously provided by professor Theresa Whiteside (PCI). Cells were cultured In RPM 1640 medium with HEPES and L-glutamine (Lonza, Basel) supplemented by $10 \%$ heat inactivated fetal bovine serum (FBS - Gibco, Life Technologies) and antibiotics (PE/Strept/Fungizone 10K/!0K/25 $\mu$ g, Lonza Basel). Cell lines were maintained in humidified incubator at $37^{\circ} \mathrm{C}$ in $5 \% \mathrm{CO}_{2}$ environment. Cells were collected at $>90 \%$ con-

Correspondence: Prof. Jan Żeromski, Chair and Department of Clinical Immunology, Poznan University of Medical Sciences, Rokietnicka 5D, 60-806 Poznań, Poland, e-mail: jzeromski@ump.edu.pl 
Table 1. Values of fold changes of TLR expression levels in investigated cell lines comparing to calibrator (LX2 cell line)

\begin{tabular}{lccc}
\hline Cell line & TLR-2/b2M & TLR-3/b2M & TLR-4/b2M \\
\hline PCI37A & 0.002693 & 35.316601 & 0.214367 \\
\hline PCI37B & 1.097103 & 34.196888 & 0.002682 \\
\hline PCI30 & 0.384053 & 48.409071 & 0.010551 \\
\hline PCI4B & 0.341289 & 99.188405 & 0.016948 \\
\hline PCI1 & 0.860288 & 19.321744 & 0.021763 \\
\hline Hep2 & 0.000238 & 2.946083 & 0.021040 \\
\hline
\end{tabular}

fluence by $0.25 \%$ trypsin with EDTA (Gibco) digestion and centrifugation for min at $1500 \mathrm{rpm}$, resuspended in RPMI medium and counted using haemocytometer and $0.4 \%$ trypan blue. Cell viability was $100 \%$.

\section{RNA isolation, cDNA synthesis and Real-time PCR}

Total RNA was isolated from harvested cell lines using PureLink Micro-to-Midi Total RNA Purification kit (Invitrogen) as described by manufacturer. Isolated RNA was quantified on spectrophotometer (Nanodrop ND-1000). Equal quantities of isolated RNA $(1 \mu \mathrm{g})$ were reverse transcribed using the Quantitect Reverse Transcription kit (Qiagen). The obtained cDNA was used as a template for quantitative real-time PCR. Primers used in the reaction $[9,10]$ were:

TLR-2 (CCCATTGCTCTTTCACTGCT, CTTCCTTGGA GAGGCTGATG),

TLR-3 (TGGTTGGGCCACCTAGAAGTA, TCTCCATT CCTGGCCTGTG),

TLR-4 (CTGCAATGGATCAAGGACCA, TTATCTGAA GGTGTTGCACATTCC), B2M (TGCTGTCTCCATGTTTGATGTATCT, TCTCTG CTCCCCACCTCTAAGT).

The reaction was performed on RotorGene 6000 (Corbett Research) system using QuantiFast SYBR Green PCR Kit (Qiagen). The raction conditions: $10 \mathrm{~min}$ at $95^{\circ} \mathrm{C}$, 45 cycles of $5 \mathrm{sec}$ at $95^{\circ} \mathrm{C}, 1 \mathrm{~min}$ at $60^{\circ} \mathrm{C}$, finished with melt analysis. Real-time PCR conditions were used to test relative levels of three TLRs (TLR-2, TLR-3, TLR-4) in selected human carcinoma cell lines. Standard curves, reaction efficiency and gene expression levels were calculated by the software provided with the used RotorGene platform.

\section{Results and discussion}

As a calibrator for standard curves preparation we used RNA isolated from LX2 cell line (hepatic stellate cells) generously provided by prof. Rifaat Safadi, Jerusalem, Israel. The quantity of given TLR in relation to B2M was measured in case of LX2 cell line and set as value " $1 \times$ " (cali-
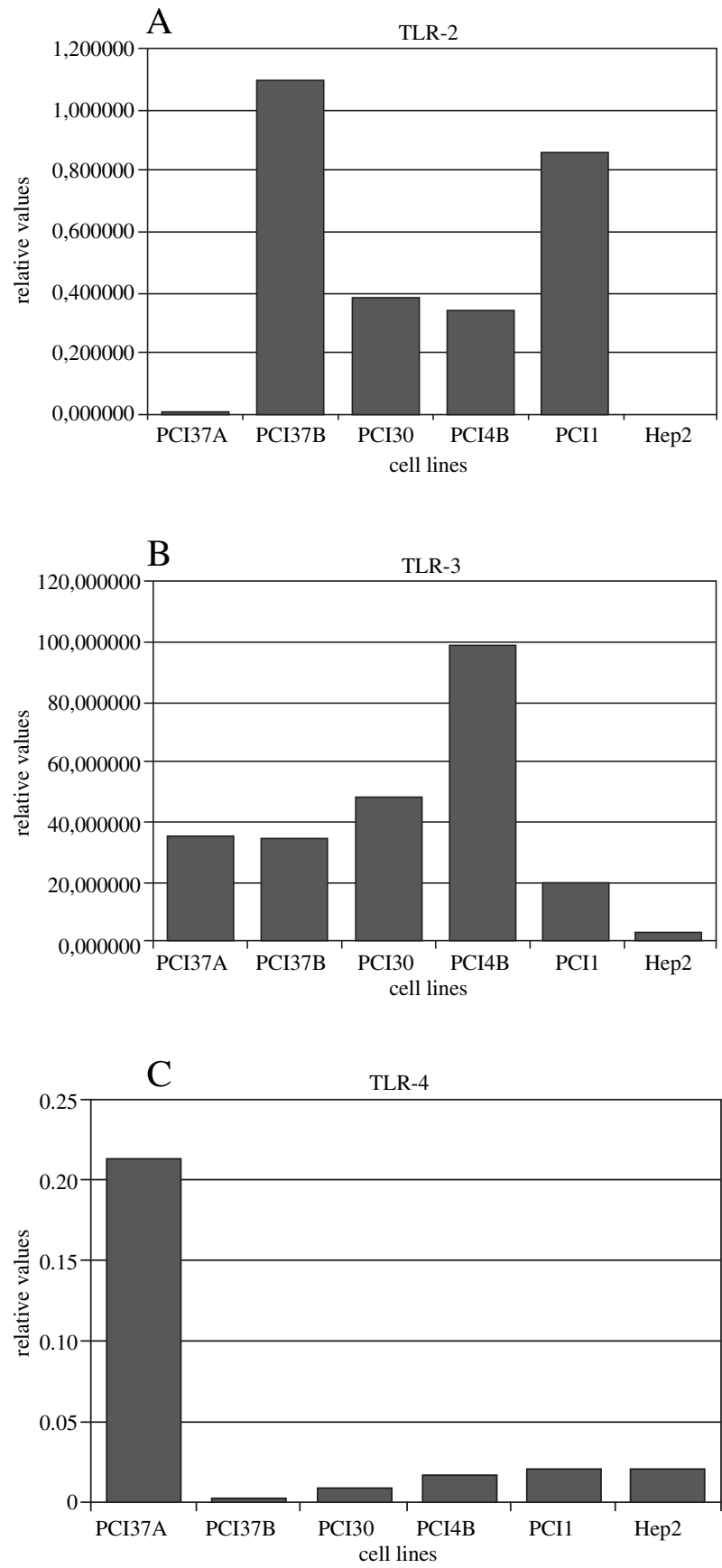

Fig. 1. Graphs presenting fold changes of TLR expression levels in investigated cell lines comparing to calibrator (LX2 cell line)

brator) as described in "RotorGene 6000 Operator Manual". The same was done for investigated carcinoma cell lines. Obtained results shown in Table 1 and on Fig. 1 are presented as fold changes of given TLR expression in carcinoma cell lines comparing to LX2 cell line. 
As it can be seen from the Table 1 and Fig. 1, mRNA of TLRs studied differed significantly among six carcinoma cell lines tested. In general, TLR-3 mRNA was the most frequently expressed while TLR-4 one has shown high relative value in one cell line only (PCI37A). It suggests that in any future attempts using TLR ligand in tumor immunotherapy it seems obligatory the determination TLR mRNA. Such immunotherapeutic attempts have been done but with unequivocal results. For example TLR-9 ligand, CpG-ODN was shown to induce activation of lung cancer cell lines, with apparently positive response [11]. On the other hand, it has been shown by some of us that TLR-4 promotes tumor growth in a head and neck cell line carcinoma model [12]. Nevertheless, there is growing interest in application of TLR ligands or agonists as therapeutic agents in pathological conditions and in particular, in malignancies $[13,14]$.

This work was supported by grants no. NN 401183333 (to JZ) and no. NN 401535740 (to IM-L) founded by the Ministry of Science and Higher Education, Poland.

\section{References}

1. Beutler B (2004): Toll-like receptors and their place in immunology. Nature 430: 498-518.

2. Ioannou S, Voulgarelis M (2010): Toll-like receptors, tissue injury, and tumourigenesis. Mediators Inflamm pii: 581837.

3. Rydberg C, Månsson A, Uddman R, et al. (2009): Toll-like receptor agonists induce inflammation and cell death in a model of head and neck squamous cell carcinomas. Immunology 128 (1 Suppl): e600-611.

4. Zeromski J, Mozer-Lisewska I, Kaczmarek M (2008): Significance of Toll-like receptors expression in tumor growth and spreading: a short review. Cancer Microenviron 1: 37-42.

5. Cherfils-Vicini J, Platonova S, Gillard M, et al. (2010): Triggering of TLR7 and TLR8 expressed by human lung cancer cells induces cell survival and chemoresistance. J Clin Invest 120: $1285-1297$.

6. Umemura N, Zhu J, Mburu YK, et al. (2012): Defective NF-kB signaling in metastatic head and neck cancer cells leads to enhanced apoptosis by double-stranded RNA. Cancer Res 72: 45-55.

7. Hamm S, Rath S, Michel S, Baumgartner R (2009): Cancer immunotherapeutic potential of novel small molecule TLR7 and TLR8 agonists. J Immunotoxicol 6: 257-265.

8. Sikora J, Frydrychowicz M, Kaczmarek M, et al (2010): TLR receptors in laryngeal carcinoma - immunophenotypic, molecular and functional studies. Folia Histochem Cytobiol 48: 624-631.

9. Staquet MJ, Durand SH, Colomb E, et al. (2008): Different roles of odontoblasts and fibroblasts in immunity. J Dent Res 87: 256-261.

10. Tanaka S, Honda Y, Honda M (2007): Identification of differentially expressed genes in blood cells of narcolepsy patients. Sleep 30: 974-979.

11. Droemann D, Albrecht D, Gerdes J, et al. (2005): Human lung cancer cells express functionally active Toll-like receptor 9 . Respir Res 6: 1-10.
12. Szczepanski MJ, Czystowska M, Szajnik M, et al. (2009): Triggering of Toll-like receptor 4 expressed on human head and neck squamous cell carcinoma promotes tumor development and protects the tumor from immune attack. Cancer Res 69: 3105-3113.

13. Meyer T, Stockfleth E (2008): Clinical investigations of Tolllike receptor agonists. Expert Opin Investig Drugs 17: 10511065.

14. Hedayat M, Takeda K, Rezaei N (2012): Prophylactic and therapeutic implications of toll-like receptor ligands. Med Res Rev 32: 294-325. 